\title{
High-intensity sprint training inhibits mitochondrial respiration through aconitase inactivation
}

\author{
Filip J. Larsen, ${ }^{* \dagger, 1}$ Tomas A. Schiffer, ${ }^{*}$ Niels Ørtenblad, ${ }^{\ddagger}$ Christoph Zinner, ${ }^{\S, \oplus}$ \\ David Morales-Alamo," Sarah J. Willis, ${ }^{\S}$ Jose A. Calbet, ${ }^{\|}$Hans-Christer Holmberg, ${ }^{\S}$ \\ and Robert Boushel ${ }^{\dagger, \#}$ \\ *Department of Physiology and Pharmacology, Karolinska Institute, Stockholm, Sweden; ${ }^{\dagger}$ Swedish \\ School of Sport and Health Sciences, Stockholm, Sweden; ${ }^{\dagger}$ Institute of Sports Science and Clinical \\ Biomechanics, Muscle Research Cluster, University of Southern Denmark, Odense, Denmark; ${ }^{\circledR}$ Swedish \\ Winter Sports Research Centre, Department of Health Sciences, Mid Sweden University, Östersund, \\ Sweden; ${ }^{\top}$ Department of Sport Science, Julius Maximilians University, Würzburg, Germany; ${ }^{\|}$Research \\ Institute of Biomedical and Health Sciences (IUIBS), Las Palmas de Gran Canaria, Canary Islands, Spain; \\ and ${ }^{\#}$ School of Kinesiology, University of British Columbia, Vancouver, British Columbia, Canada
}

ABSTRACT Intense exercise training is a powerful stimulus that activates mitochondrial biogenesis pathways and thus increases mitochondrial density and oxidative capacity. Moderate levels of reactive oxygen species (ROS) during exercise are considered vital in the adaptive response, but high ROS production is a serious threat to cellular homeostasis. Although biochemical markers of the transition from adaptive to maladaptive ROS stress are lacking, it is likely mediated by redox sensitive enzymes involved in oxidative metabolism. One potential enzyme mediating such redox sensitivity is the citric acid cycle enzyme aconitase. In this study, we examined biopsy specimens of vastus lateralis and triceps brachii in healthy volunteers, together with primary human myotubes. An intense exercise regimen inactivated aconitase by $55-72 \%$, resulting in inhibition of mitochondrial respiration by $50-65 \%$. In the vastus, the mitochondrial dysfunction was compensated for by a 15-72\% increase in mitochondrial proteins, whereas $\mathrm{H}_{2} \mathrm{O}_{2}$ emission was unchanged. In parallel with the inactivation of aconitase, the intermediary metabolite citrate accumulated and played an integral part in cellular protection against oxidative stress. In contrast, the triceps failed to increase mitochondrial density, and citrate did not accumulate. Instead, mitochondrial $\mathrm{H}_{2} \mathrm{O}_{2}$ emission was decreased to $40 \%$ of the pretraining levels, together with a 6-fold increase in protein abundance of catalase. In this study, a novel mitochondrial stress response was highlighted where accumulation of citrate acted to preserve the redox status of the cell during periods of intense exercise.-Larsen, F. J., Schiffer, T. A., Ørtenblad, N., Zinner, C., Morales-Alamo, D., Willis, S. J., Calbet, J. A., Holmberg, H.-C., Boushel, R. High-intensity sprint training inhibits mitochondrial respiration through

Abbreviations: ADP, adenosine diphosphate; AU, arbitrary units; BCA, bicinchoninic acid (assay); BSA, bovine serum albumen; COX, cytochrome $c$ oxidase; CS, citrate synthase; ETS, electron transport system; FBS, fetal bovine serum; GSH, reduced form of glutathione; GSSG, oxidized form of glutathione; HIT, high-intensity training; HRP, horseradish peroxidase;

(continued on next page) aconitase inactivation. $F A S E B J .30,417-427$ (2016). www.fasebj.org

Key Words: exercise $\cdot$ mitochondrial dysfunction $\cdot$ reactive oxygen species $\cdot$ citrate

Aerobic exercise training is well established as a potent stimulus of mitochondrial biogenesis pathways, and it improves cardiorespiratory fitness, insulin sensitivity, and physical performance $(1,2)$. A long-held view has been that changes in mitochondrial content and activation by ADP are the only means by which skeletal muscle oxidative capacity increases or decreases. This view has been challenged recently, as alterations in mitochondrial quality, coupling, and efficiency, commonly termed intrinsic mitochondrial properties, have been found after training or dietary interventions (3-5). Several recent studies have shown that the formation of physiologic concentrations of reactive oxygen species (ROS) is an important cellsignaling process that is indispensable for the activation of mitochondrial biogenesis and cellular proliferation (6). These positive effects of moderate levels of ROS are in contrast to the detrimental effects of excessive oxidative stress associated with several pathologic conditions (7) and extreme endurance events $(8,9)$. Although the topic is controversial (10), there is a dynamic balance between optimal exercise intensities that yield moderate oxidative stress with beneficial adaptations and excessive exercise that produces severe oxidative stress and maladaptation. This interesting dose-response relationship between ROS levels and cellular outcome is an area of intense research (11).

Despite reports of robust health-promoting effects, intense exercise reproducibly increases oxidative stress

\footnotetext{
${ }^{1}$ Correspondence: Department of Physiology and Pharmacology, Karolinska Institute, Stockholm, Sweden, Nanna Svartz väg 2, SE-171 77 Stockholm, Sweden. E-mail: filip.larsen@ki.se or filip.larsen@gih.se

doi: $10.1096 /$ fj.15-276857

This article includes supplemental data. Please visit http:// www.fasebj.org to obtain this information.
} 
(12), indicated by the elevated oxidation product malondialdehyde and oxidation of glutathione immediately after exercise (13). The elevated oxygen consumption during intense aerobic exercise therefore increases the generation of ROS. Both NADPH oxidases and xanthine oxidoreductase have been found to be activated during exercise and to contribute significantly to total ROS stress (14). Further, mitochondria from skeletal muscle show higher ROS production after contractions than that shown in the resting state (15). Thus, the production of mitochondrial ROS during exercise initiates a potential signaling cascade where the level of activity (i.e., oxygen turnover), induces a feedback signal to the nucleus, regulating the abundance of mitochondrial proteins that enable cells to meet the demand for energy.

Structures that promptly adapt to changes in oxidative stress are necessary to maintain homeostasis. Aconitase is a redox-sensitive enzyme primarily located in the mitochondrial tricarboxylic acid (TCA) cycle, where it facilitates the isomerization of citrate to isocitrate via cis-aconitase and subsequent delivery of NADH to the electron transport system (ETS). Aconitase has an active $\left[\mathrm{Fe}_{4} \mathrm{~S}_{4}\right]^{2+}$ cluster that is rapidly inactivated into $\left[\mathrm{Fe}_{3} \mathrm{~S}_{4}\right]^{+}$through oxidation by superoxide, peroxynitrite, and $\mathrm{H}_{2} \mathrm{O}_{2}$, constituting a redox-sensitive regulation of the rate-limiting enzyme in the TCA cycle. The location of a redoxsensitive enzyme in the TCA cycle implies that aconitase can act as a rheostat that modulates mitochondrial metabolism by its interaction with ROS (16). We sampled human muscle from tissue samples taken before and after a short-term high-intensity training program, to assess the resilience of mitochondrial respiration and aconitase to high-intensity training and redox stress. By using samples from both the vastus lateralis and the triceps brachii, we sought to identify the muscle-specific response and the delineation between the optimal redox stress that induces mitochondrial biogenesis and the excessive ROS stress that leads to maladaptation. We used cultured primary myotubes to assess the role of the endogenous increases in citrate concentrations in the defense against excessive ROS stress. We further sought to distinguish the mitochondrial response to high levels of ROS induced by the intense training program and the cellular adaptations that maintain cell integrity.

\section{MATERIALS AND METHODS}

\section{Subjects}

Twelve healthy male subjects [mean age, $24.2 \pm 3.8 \mathrm{yr}$; height, $183.8 \pm 6.8 \mathrm{~cm}$; weight, $80.0 \pm 14.7 \mathrm{~kg}$, and body mass index, $\left.23.6 \pm 0.9 \mathrm{~kg} / \mathrm{m}^{2}\right]$ volunteered for the study. The subjects classified themselves as untrained or only moderately active. All subjects gave written consent after being informed of the study procedure. The study was approved by the Regional Ethics Review Board in Umeå, Sweden, and was performed in conformity

(continued from previous page)

MHC, myosin heavy chain; RER, respiratory exchange ratio; ROS, reactive oxygen species; TBS, Tris-buffered saline; TBST, TBS-Tween 20; TCA, tricarboxylic acid; $V_{2 p e a k}$, maximum oxygen consumption with the principles of the Declaration of Helsinki. This study was a part of a larger study involving 16 subjects; however, mitochondrial respiration and biochemical measurements were undertaken on tissue samples obtained from 12 subjects. Therefore, all data reported in this study are from these 12 subjects, but samples from 3 additional subjects were used for the isolation of myogenic satellite cells and culturing of myotubes.

\section{Testing procedure: high-intensity training}

To adjust the ergometers (Schoberer Rad Messtechnik SRM, GmbH, Jülich, Germany) for leg and arm cycling for all subsequent testing and to become familiar with the equipment and procedures, the subjects visited the laboratory 2 times. The subject, seated position arm cycling, was positioned in a way that the axle of the crank was positioned just below the level of the heart and with a comfortable elbow angle when the cranks were in a horizontal position (17). Performance tests were executed before and after the high-intensity training (HIT) intervention. The subjects performed 4 consecutive 4 min sessions of exercise (100 rpm) at submaximal intensity, adjusted so that the respiratory exchange ratio (RER) in the last session was $>1.0$. After a rest of $10 \mathrm{~min}$, maximum oxygen consumption $\left(V_{\mathrm{O}_{2 \text { peak }}}\right)$ was determined by an incremental test in which the subject performed to volitional exhaustion, as follows: arm cycling started at a work load of $20 \mathrm{~W}$, where the subjects freely chose the pedal frequency (within the range of 70-105 rpm) with the workload increased by $10 \mathrm{~W}$ each $30 \mathrm{~s}$. Leg cycling started at $60 \mathrm{~W}$, with an increase of $25 \mathrm{~W}$ each $30 \mathrm{~s}$. $\mathrm{VO}_{2 \text { peak }}$ was calculated from the plateau of oxygen uptake with the following criteria: an elevation of $\mathrm{VO}_{2}$ of $<2.1 \mathrm{ml} \cdot \mathrm{min}^{-1} \cdot \mathrm{kg}^{-1}$ with increasing work load: RER $>1.1$, heart rate within $\pm 2.5 \%$ of the age-adjusted maximum, and capillary blood lactate concentration of $6 \mathrm{mM}$ (18). Three minutes after the participants experienced exhaustion, achievement of $V_{\text {2peak }}$ was verified by having them pedal for as long as possible at the peak resistance attained during the incremental test $+10 \mathrm{~W}$ during arm cranking and $+25 \mathrm{~W}$ during leg cycling. On the second day of testing and to evaluate the effect of the intervention on passive recovery between all-out efforts, the subjects performed 2 Wingate anaerobic tests separated by 4 min of recovery. The subjects remained seated and were encouraged verbally by the researchers during the tests. The gas-exchange equipment was calibrated before the tests with a mixture of $4.5 \%$ $\mathrm{CO}_{2}$ and $16 \% \mathrm{O}_{2}$ and a 3-L syringe (Hans Rudolph Inc., Kansas City, KS, USA). The first testing procedure was performed $3 \mathrm{~d}$ after the baseline specimen was extracted and $2 \mathrm{~d}$ before the first training session. The posttest procedure was completed $2 \mathrm{~d}$ after the 6 th training session, and then a last training session was performed to allow for standardized training stimuli and time span before the posttest biopsy was performed $40 \mathrm{~h}$ later.

\section{Training schedule}

The sessions included both arm and leg cycling (separated by $1 \mathrm{~h}$ of recovery) on 7 separate days during a $15 \mathrm{~d}$ period. Each subject performed $30 \mathrm{~s}$ maximum sprints separated by $4 \mathrm{~min}$ of rest: 4 such sprints with both the arms and legs on training $\mathrm{d} 1$ and 2, 5 sprints were performed on $\mathrm{d} 3$ and 4 , and 6 sprints were performed on d 5, 6, and 7 .

\section{Extraction of tissue specimens}

Biopsies were performed before the first training session and $40 \mathrm{~h}$ after the last training session. The samples were extracted with a Bergström needle under local anesthesia (2-3 ml 2\% mepivacaine) in randomized order from both sides of the vastus lateralis and triceps brachii (distal portion of the lateral head). After the 
tissue was dried on filter paper, it was divided into 3 pieces: the first for immunoblot analysis, the second for enzymatic activities (both snap-frozen in liquid $\mathrm{N}_{2}$ ), and the third for mitochondrial isolation (placed in ice-cold isolation medium and used immediately).

\section{Immunoblot analysis}

Muscle samples were homogenized in a blender (Bullet Blender Blue; Next Advance, Averill Park, NY, USA) in ice-cold lysis buffer [2 mM 4-(2-hydroxyethyl)-1-piperazineethanesulfonic acid (HEPES) (pH 7.4), 1 mM EDTA, 5 mM EGTA, $10 \mathrm{mM} \mathrm{MgCl}_{2}$, $50 \mathrm{mM} \beta$-glycerophosphate, $1 \%$ Triton X-100, $1 \mathrm{mM} \mathrm{Na}_{3} \mathrm{VO}_{4}$, $2 \mathrm{mM}$ DTT, and $1 \%$ phosphatase inhibitor cocktail (P-2850; Sigma-Aldrich, St. Louis MO, USA) ]. Homogenates were centrifuged at 10,000 $\mathrm{g}$ at $10 \mathrm{~min}$. Supernatant was collected and stored at $-80^{\circ} \mathrm{C}$ until analyzed. To determine protein concentration of the homogenates, supernatant was diluted 1:100 in distilled water and analyzed with a bicinchoninic acid (BCA) protein assay (Micro BCA assay kit; Thermo Fisher Scientific, Waltham MA, USA). Samples were adjusted by adding lysis buffer to obtain similar protein concentration followed by dilution in Laemmli sample buffer [ $125 \mathrm{mM}$ Tris-HCl 4\% SDS, $0.04 \%$ bromphenol blue, $20 \%$ glycerol, and 4\% 2-mercaptoethanol ( $\mathrm{pH}$ 6.8) ]. After the samples were heated at $95^{\circ} \mathrm{C}$ for $5 \mathrm{~min}$, they were loaded on precast gradient gels (Criterion TGX, 4-20\% acrylamide; Bio-Rad, Hercules, CA, USA). The electrophoresis was run at $175 \mathrm{~V}$ [25 mM Tris base, $192 \mathrm{mM}$ glycine, and $3.5 \mathrm{mM}$ SDS ( $\mathrm{pH} 8.3)$ ], whereupon the proteins were transferred to PVDF membranes (Immun-Blot PVDF; Bio-Rad) for $1.5 \mathrm{~h}$ (300 mA) (25 mM Tris base, and $192 \mathrm{mM}$ glycine). Membranes were blocked in Tris-buffered saline [(TBS; $20 \mathrm{mM}$ Tris base and $137 \mathrm{mM} \mathrm{NaCl}(\mathrm{pH} \mathrm{7.6)}$ ] containing $5 \%$ nonfat dry milk and $0.1 \%$ Tween 20 for $1 \mathrm{~h}$ before incubation with commercially available primary antibodies overnight or $1.5 \mathrm{~h}$ in room temperature (1:1000 in TBS, $2.5 \%$ milk). The membranes were washed in TBST with milk and incubated with secondary antibodies for $1 \mathrm{~h}$ (1:10,000 in TBST with milk). After the membranes were washed in TBST, the target proteins were visualized by chemiluminescent detection (Chemidoc MP Imaging System; Bio-Rad) and analyzed with software Image Lab 5.0 (Bio-Rad). After reanalyzing the same PVDF membrane for different proteins, we stripped the membranes by using Restore Western Blot Stripping Buffer (Thermo Fisher Scientific), according to the manufacturers' instructions, and subsequently reprobed them with the following primary antibodies: citrate synthetase, ab96600 (Abcam, Cambridge MA, USA) cytochrome $c$ oxidase (COX)-IV-1 (4850; Cell Signaling Technology, Danvers, MA, USA), mitochondrial trifluoroacetic acid (mtTFA; ab47517; Abcam), AMPK $\alpha$ 1 (ab3759), phospho-AMPK (ab133448), PGCl $\alpha$ (ab 54481), and catalase (ab16731; Abcam). Secondary antibodies were anti-mouse horseradish peroxidase (HRP)-linked antibody (7076) and antirabbit HRP-linked antibody (7074; both from Cell Signaling Technology).

\section{Isolation of primary myogenic satellite cells}

The muscle samples were placed in PBS at $4^{\circ} \mathrm{C}$ overnight. The sample was then washed in PBS and cleared from connective tissue. A few drops of Trypsin-EDTA $0.25 \%$ (Thermo FisherGibco, Grand Island, NY, USA) were added, and the specimen was homogenized with a pair of scissors. After $7 \mathrm{ml}$ trypsin was added, the homogenate was transferred to a small beaker and put in the incubator with gentle stirring for 20-30 min. After sedimentation, the supernatant was collected, and the trypsin was blocked with a few $\mathrm{ml}$ of complete medium to a final concentration of at least $2 \%$ fetal bovine serum (FBS). After centrifugation, the cells were resuspended in $10 \mathrm{ml}$ cell medium and plated in a $10 \mathrm{~cm}^{2}$ Petri dish for $20-30 \mathrm{~min}$, to let adherent cells attach. The cells remaining in suspension were then transferred to a $25 \mathrm{~cm}^{2}$ cell culture flask. The cell culture medium consisted of $50 \%$ DMEM (low glucose) and 50\% F12 (both from Thermo FisherGibco), containing $50 \mathrm{U} / \mathrm{ml}$ penicillin, $50 \mathrm{U} / \mathrm{ml}$ streptomycin, $1.25 \mu \mathrm{g} / \mathrm{ml}$ amphotericin, and 20\% FBS. For differentiation, the medium was exchanged with a similar medium containing $2 \%$ FBS for $5 \mathrm{~d}$ before the cells were harvested or treated.

\section{Respirometric analysis mitochondria}

Mitochondrial isolation was performed as published (19). Respirometric analysis on isolated mitochondria was performed by high-resolution respirometry (O2-K; Oroboros, Innsbruck, Austria) in a respiration medium containing $0.5 \mathrm{mM}$ EGTA, $3 \mathrm{mM} \mathrm{MgCl}_{2}$, $60 \mathrm{mM}$ potassium-lactobionate, $20 \mathrm{mM}$ taurine, $10 \mathrm{mM} \mathrm{KH}_{2} \mathrm{PO}_{4}$, $20 \mathrm{mM}$ HEPES, $110 \mathrm{mM}$ sucrose, and $1 \mathrm{~g} / \mathrm{L}$ bovine serum albumen (BSA). Saturated levels of pyruvate $(5 \mathrm{mM})$, malate $(1 \mathrm{mM})$, and ADP $(2.5 \mathrm{mM})$ were used as substrates for the determination of complex I-mediated respiration, together with succinate $(10 \mathrm{mM})$ for complex I+II-mediated respiration. Mitochondrial experiments were performed at an oxygen pressure of $15-20 \mathrm{kPa}$ $\mathrm{O}_{2}$ in the chamber.

\section{Mitochondrial yield}

After differential centrifugation, the final mitochondrial pellet was resuspended in preservation solution at $0.6 \mu \mathrm{l} / \mathrm{mg}$ initial muscle tissue weight. Mitochondrial yield was estimated from the protein concentration per microliter preservation solution, as determined by the BCA method, according to the manufacturer's instructions (Thermo Fisher Scientific).

\section{Respirometric analysis on differentiated primary myotubes}

Respirometric analysis on mitochondria and differentiated cultured primary myotubes was performed by high-resolution respirometry (O2-K; Oroboros). Basal cell respiration was determined in respiration medium (contents as described earlier). After basal cell respiration, the cells were permeabilized with digitonin. Saturating levels of pyruvate $(5 \mathrm{mM})$, malate $(1 \mathrm{mM})$, and succinate $(10 \mathrm{mM})$ were used as substrates (Sigma-Aldrich), together with ADP $(2.5 \mathrm{mM})$. The cells were exposed to $\mathrm{H}_{2} \mathrm{O}_{2}$ at various concentrations $(20-200 \mu \mathrm{M})$ while oxygen consumption was measured.

\section{Mitochondrial $\mathrm{H}_{2} \mathrm{O}_{2}$ emission}

Oxygen consumption and $\mathrm{H}_{2} \mathrm{O}_{2}$ production were measured simultaneously $\left(\mathrm{O}_{2}-\mathrm{K}\right.$ with fluorometer; Oroboros $) . \mathrm{H}_{2} \mathrm{O}_{2}$ was measured fluorometrically with the extrinsic fluorophore Amplex Ultrared (10 $\mu \mathrm{M}$; Thermo Fisher Scientific) in combination with $\mathrm{HRP}(1 \mathrm{U} / \mathrm{ml})$. Calibration of the $\mathrm{H}_{2} \mathrm{O}_{2}$ signal was performed by stepwise increases of $0.1 \mu \mathrm{M} \mathrm{H}_{2} \mathrm{O}_{2}$ obtained from a prepared stock solution [ $40 \mu \mathrm{M} \mathrm{H}_{2} \mathrm{O}_{2}$ (Sigma-Aldrich), $10 \mu \mathrm{M}$ $\mathrm{HCl}]$.

\section{Oxidative markers in muscle tissue}

Several commercial kits were used to measure different oxidative markers in muscle homogenates. A ratio-detection kit (Abcam) was used for measuring the ratio of the oxidized to the reduced form of glutathione (GSSG:GSH). Protein carbonylation was measured with a protein carbonyl content assay kit (Sigma-Aldrich). An 
aconitase assay kit (Abcam) was used to determine aconitase activity. In all of the commercial kits, the manufacturers' instructions were followed, except for some modifications when using the Aconitase Assay Kit. To avoid reactivation of oxidized aconitase, the $\left(\mathrm{NH}_{4}\right)_{2} \mathrm{Fe}\left(\mathrm{SO}_{4}\right)_{2}$ and cysteine-HCl in the assay were excluded.

\section{Citrate synthase activity measurements}

Enzyme activities were measured in freeze-dried muscle dissected from nonmuscle constituents and homogenized on ice in a $50 \mathrm{mM}$ phosphate buffer containing $1 \mathrm{mM}$ EDTA and $0.05 \% \mathrm{v} / \mathrm{v}$ Triton X-100 (pH 7.4). To disrupt the mitochondria and expose the citrate synthase (CS), homogenates were freeze thawed 4 times with liquid nitrogen. CS activity was determined by the addition of oxaloacetate to a buffer solution containing muscle homogenate, DTNB (5,5'-dithiobis-2-nitrobenzoic acid) buffer, and acetyl-CoA. The rate change in absorbance $(405 \mathrm{~nm})$ was monitored over 6 min (model 650; Beckman Coulter, Pasadena, CA, USA), converted into enzyme activity rates, and expressed as a percentage of the pretraining value.

\section{Citrate levels in muscle homogenates}

A citrate assay kit (MAK057-1KT; Sigma-Aldrich) was used to determine the concentration of citrate in the muscle homogenates, according to the manufacturer's instructions. In brief, the protein content of muscle homogenates was measured as indicated above, and an appropriate amount of homogenate was loaded into a $10 \mathrm{kDa}$ separation filter and spun at $13,900 \mathrm{~g}$ for $25 \mathrm{~min}$. The citrate content of the eluate was then analyzed by spectrophotometry, according to the manufacturer's instructions, and related to the initial protein content in the sample.

\section{Statistical analysis}

Results are expressed as means \pm SEM. Student's $t$ test or 1-way ANOVA was used for statistical analyses (Prism 5.0; GraphPad, San Diego, CA, USA). $P<0.05$ denoted statistical significance.

\section{RESULTS}

HIT increases work capacity, mitochondrial density, and oxidative enzyme activity, without change in myosin heavy chain composition

After training, aerobic fitness, measured as $\mathrm{VO}_{2 \text { peak }}$, increased by $6 \%$ during incremental leg cycling and by $12 \%$ during arm cranking (Fig. 1A; both $P<0.001$ ). In parallel, the mean power outputs during repeated $30 \mathrm{~s}$ sprints increased by $4 \%$ in the legs $(P<0.01)$ and $8 \%$ in the arms $(P<0.05)$ (Fig. $1 B)$. After training, the mitochondrial proteins CS, mitochondrial transcription factor A (TFAM), and COXIV increased after training in the vastus but not in the triceps (Fig. $1 C, D$ ). Likewise, there was a tendency toward elevated CS activity after training, compared with the pretraining level in the vastus $(P=0.07)$, but not in the triceps. We found no evidence of increased protein levels of peroxisome proliferator-activated receptor gamma coactivator (PGC)-1 $\alpha$ [before training, $105 \pm 20$ arbitrary units (AU); after training, $104 \pm 21$ AU], AMPK (before training, $64 \pm 20 \mathrm{AU}$; after training, $53 \pm 17 \mathrm{AU}$ ), or phospho-AMPK (before training, $44 \pm 14 \mathrm{AU}$; after training $67 \pm 21 \mathrm{AU})$ (data not shown), indicating that the

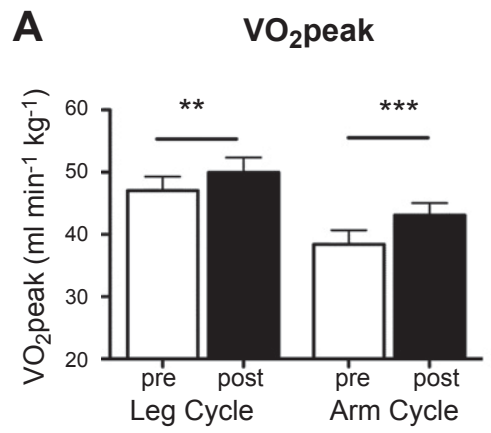

\section{Mitochondrial density markers Vastus}

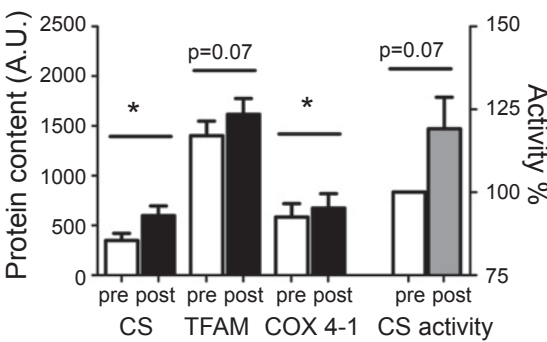

CS TFAM COX 4-1 CS activity

B

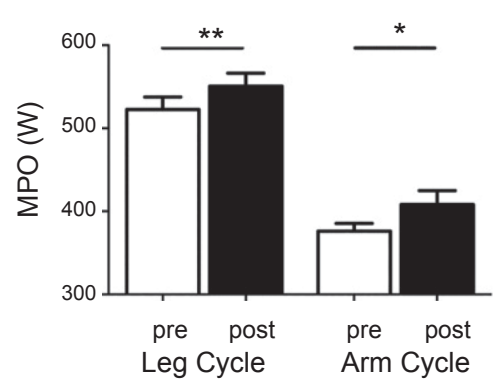

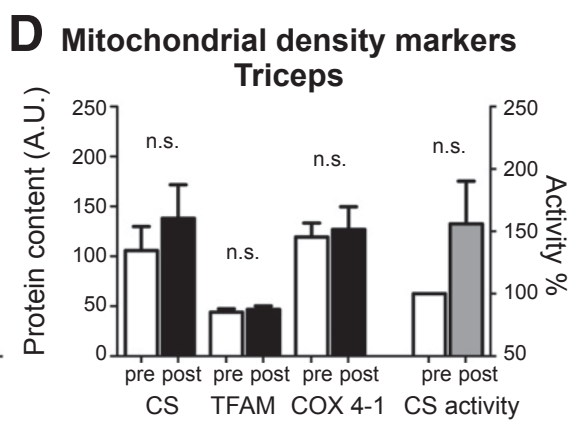

vastus lateralis

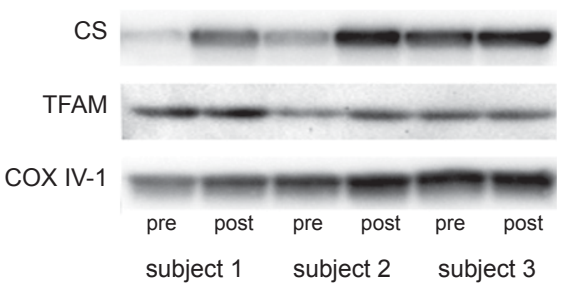

triceps brachii

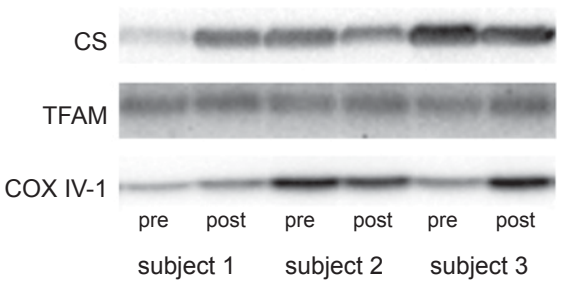

Figure 1. The effects of HIT on physiologic parameters and mitochondrial density markers in skeletal muscles. $A$ ) $V_{2} \mathrm{O}_{2 \text { peak }}$ before and after the training period. $V_{2}$ peak averaged for $30 \mathrm{~s}$ was measured during incremental exercise with a normal leg cycle ergometer, and arm $V_{2}$ peak was measured at a separate occasion with an arm-cranking ergometer in the seated position. $B$ ) Mean workload attained during $30 \mathrm{~s}$ maximum-effort sprints with the leg cycle and the arm cranking ergometer $(n=12)$. $C, D)$ Western blot analysis of 3 selected mitochondrial proteins and CS activity before (pre) and after (post) training in the vastus lateralis ( $C$ ) and triceps brachii $(D)$. Densitometric analysis of each band, normalized for protein content against Reactive Brown, revealed the variations between before and after training. CS activity was measured with a spectrophotometric approach $[n=8(D)$ and 10 $(C)$ ]; error bars, sEM. $* P<0.05$; ** $P<0.01$; *** $P<0.001$. 
posttraining specimens were extracted outside of the acute training response after the last training session.

Myosin heavy chain (MHC) composition of type I, IIa, and IIb fibers before training was $44 \pm 3,53 \pm 3$, and $3 \pm$ $1 \%$ in vastus and $28 \pm 3,65 \pm 4$, and $7 \pm 3 \%$ in triceps, respectively. The distribution of type I fibers was significantly lower $(P<0.01)$ and that of the type IIa fibers was higher $(P<0.05)$ in the triceps than in the vastus. However, training did not alter the MHC distribution in the vastus $(49 \pm 3,49 \pm 3$, and $2 \pm 1 \%)$ or in the triceps $(26 \pm$ 2, $70 \pm 2$, and $4 \pm 2 \%$ ) (data not shown).

\section{Intrinsic respiration is suppressed after HIT due to inactivation of aconitase}

An increase in mitochondrial content is a well-known adaptation to an increase in metabolic demand, but less is known about how intrinsic parameters of mitochondrial function are affected by intense training. To explore this question, we isolated mitochondria from fresh skeletal muscle tissue and analyzed the respiratory capacity and mitochondrial efficiency and function by high-resolution respirometry. After the training intervention, several indices of intrinsic mitochondrial respiration unexpectedly decreased by $50-65 \%$ in both vastus and triceps mitochondria (Fig. 2A-C, $\boldsymbol{F}-\boldsymbol{H}$ ).

To explore the mechanisms underlying the reduced intrinsic mitochondrial respiration, we tested the hypothesis that oxidative modifications of aconitase account for the inhibition of mitochondrial electron flux. Previous findings indicate that the TCA enzyme aconitase is readily inactivated in skeletal muscle by reactive species and may limit mitochondrial respiration $(20,21)$. We found that, after training, the aconitase activity expressed per milligram wet muscle decreased significantly in the triceps but not in the vastus (Fig. 2D, I). In skeletal muscle, aconitase is primarily located in the mitochondria and considering the increase in several mitochondrial proteins, we also expressed aconitase activity per milligram mitochondrial protein and found a marked decrease after training in both muscles (Fig 2E, J). Taken together, these results demonstrate profound alterations of intrinsic mitochondrial function with HIT training that are independent of global changes in mitochondrial density.

\section{HIT decreases mitochondrial $\mathrm{H}_{2} \mathrm{O}_{2}$ emission and induces markers of oxidative modification}

Mitochondrial ROS production occurs at specific sites of the ETS. We analyzed the emission of $\mathrm{H}_{2} \mathrm{O}_{2}$ in various respiratory states and loci of intact mitochondria, using Amplex red as a fluorometric probe. We found that mitochondrial ROS production was diminished in the triceps mitochondria, whereas it was unchanged in the vastus mitochondria (Fig. 3A-F).

The inactivated aconitase and compensatory decrease in mitochondrial $\mathrm{H}_{2} \mathrm{O}_{2}$ emission indicate that HIT induced a severe cellular oxidative challenge. We therefore sought
A

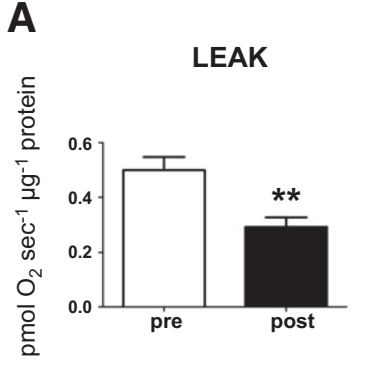

$\mathbf{F}$

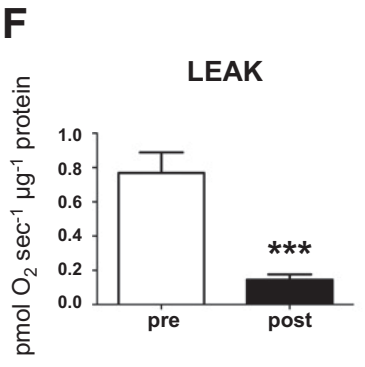

B

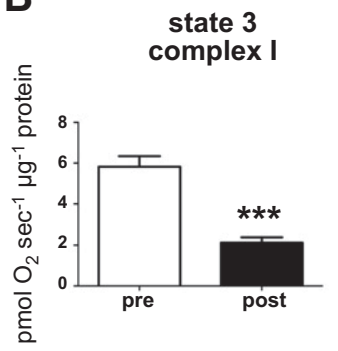

G

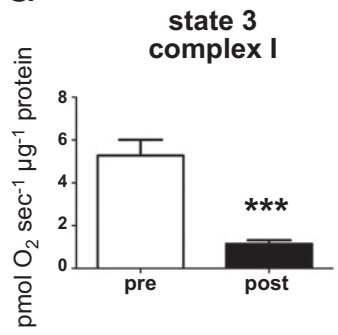

Vastus lateralis
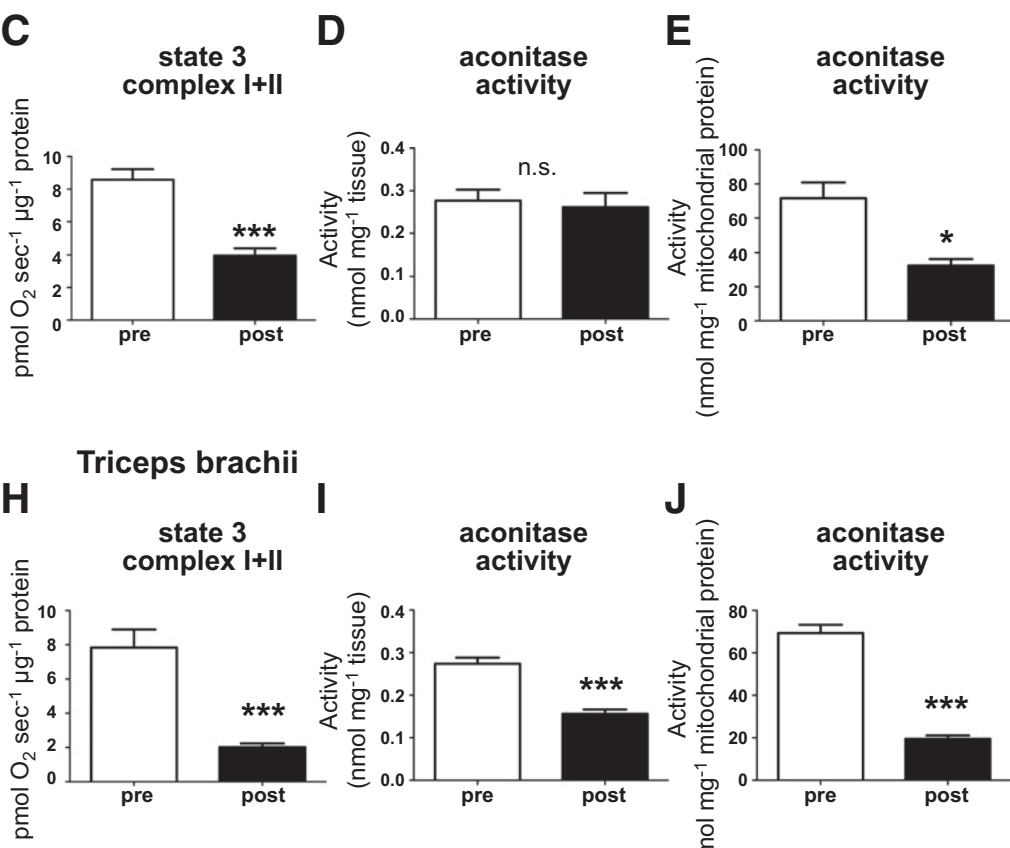

I
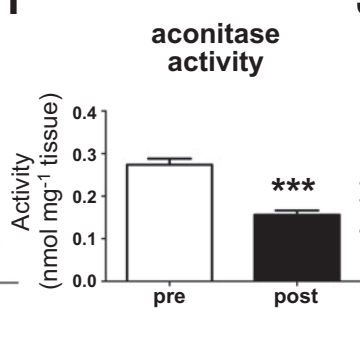

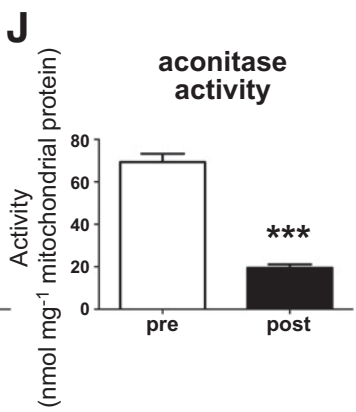

Figure 2. Intrinsic parameters of mitochondrial respiration and aconitase activity in vastus lateralis $(A-E)$ and triceps brachii $(F-J)$ before and after training. $A, F)$ Leak respiration is the respiratory rate in the presence of the respiratory substrates malate and pyruvate without addition of adenylates. $B, G$ ) State 3 complex $\mathrm{I}$ is the maximum ADP stimulated respiration rate in the presence of complex I substrates pyruvate and malate. $(C, H)$ State 3 complex I+II is similar to $(B$, $G)$, but with convergent electron flux through complex II by adding succinate $(n=12) . D, I)$ Aconitase activity is expressed per milligram wet weight tissue. $E, J)$ Aconitase activity is expressed per microgram mitochondrial protein ( $n=5$, vastus; 6 , triceps); error bars, sEM. $* P<0.05 ; * * P<0.01 ; * * * P<0.001$. 

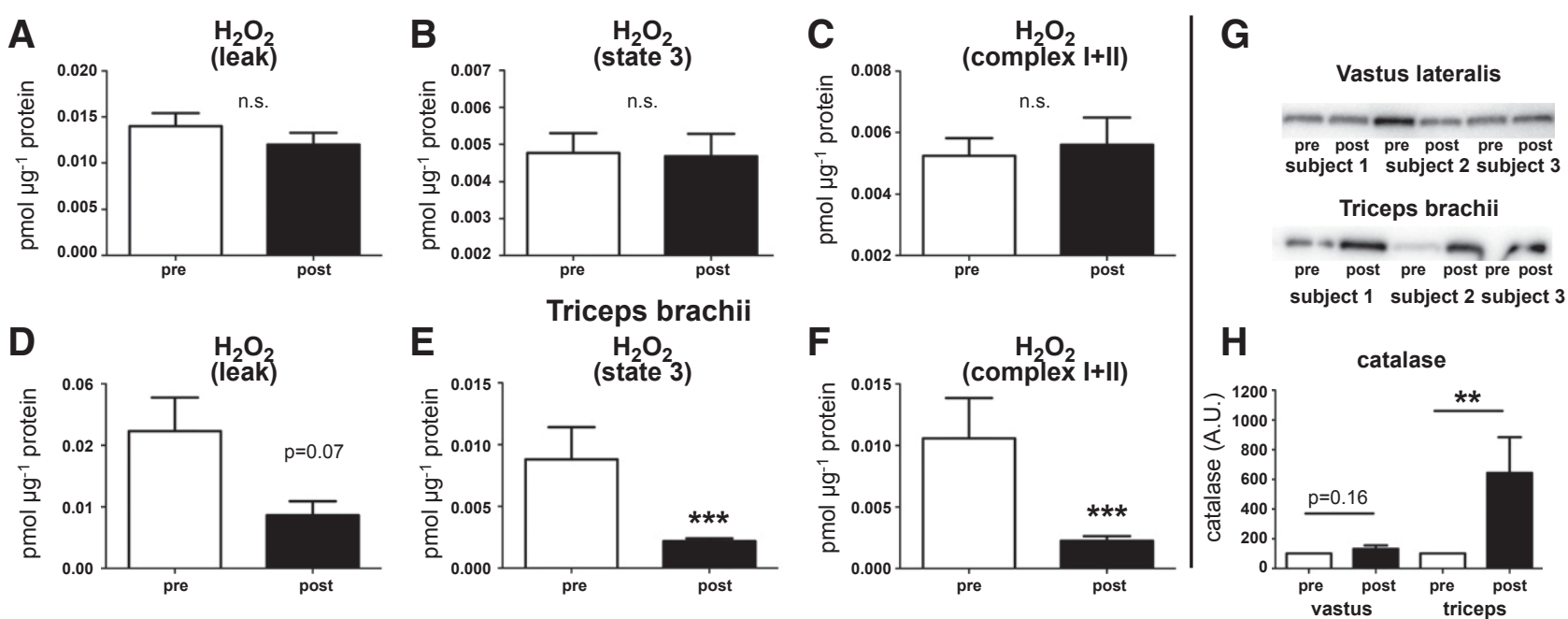

Figure 3. Release of $\mathrm{H}_{2} \mathrm{O}_{2}$ from isolated mitochondria and protein expression of catalase before (pre) and after (post) $\mathrm{HIT}_{\text {. }} \mathrm{H}_{2} \mathrm{O}_{2}$ emission was measured in isolated mitochondria with Amplex Ultrared Red used as a fluorometric probe simultaneously with the respirometric analysis of leak $(A, D)$, state $3(B, E)$ and complex $\mathrm{I}+\mathrm{III}(C, F)$ (Fig. 2 and Scheme 2). $A-F) \mathrm{H}_{2} \mathrm{O}_{2}$ emission in mitochondria from the vastus lateralis $(A-C)$ and triceps brachii $(D-F) . \mathrm{H}_{2} \mathrm{O}_{2}$ emission is expressed per microgram mitochondrial protein $(n=12)$ $G, H)$ Pre- and posttraining catalase expression in vastus and triceps. Western blot $(G)$ and densitometric analysis of each band $(H)$ revealed variations between before and after training ( $n=9$, vastus; 12 , triceps). Error bars, sEM. $* * P<0.01 ; * * * P<0.001$.

to examine the impact of the HIT training intervention on the global redox environment in the skeletal muscle biopsy specimens. We first determined the redox status of the glutathione pool, but did not find any significant changes in GSH, GSSG, or the GSSG/GSH ratio after HIT vs. before (Supplemental Fig. S1 $A-C$ ). Thereafter, we assessed more chronic oxidative protein modifications by measuring the protein carbonylation status in the tissue samples. Again, we found a trend toward more carbonylated proteins in the triceps after training $v s$. before, but in the vastus we found no such changes (Supplemental Fig S1D). We next investigated whether the endogenous antioxidative defense system was activated by HIT to maintain redox balance. We measured protein levels of catalase in the muscle samples and found a large increase after HIT $v s$. before (Fig. 3G, $H$ ). In agreement with the above findings, the increase in catalase was found only in the triceps, and not in the vastus muscles, indicating that the triceps were exposed to a more severe oxidative stress.

\section{$\mathrm{H}_{2} \mathrm{O}_{2}$ decreases complex I-driven respiration in cultured primary human myotubes}

$\mathrm{H}_{2} \mathrm{O}_{2}$ can diffuse through cell membranes and acts as a weak radical that mediates important signaling events. It has also been shown to readily inactivate aconitase. We therefore set out to determine whether low concentrations of $\mathrm{H}_{2} \mathrm{O}_{2}$ are sufficient to inhibit aconitase activity, thereby diminishing electron input into the electron carrier NADH and contributing to suppressed mitochondrial respiration. To test this hypothesis, we acutely exposed cultured primary human myotubes to several doses of $\mathrm{H}_{2} \mathrm{O}_{2}$ and measured mitochondrial respiration by high-resolution respirometry. $\mathrm{H}_{2} \mathrm{O}_{2}$ inactivated respiration in a dosedependent manner (Fig $\mathbf{4 A}$ ). This result supports the view that $\mathrm{H}_{2} \mathrm{O}_{2}$ is reactive and oxidizes mitochondrial proteins to an extent that reduces respiration.

\section{Citrate accumulates after training and protects the cell against oxidative stress}

With the finding of an increase in CS and a concomitant inactivation of aconitase that is located downstream in the TCA cycle, it can be assumed that intramuscular citrate levels should accumulate. We analyzed citrate concentration in muscle specimen homogenates and found an increase from 0.56 to $1.28 \mathrm{nmol} / \mu \mathrm{g}$ protein in the vastus from before to after training $(P=0.03$; Fig. $4 B)$. However in the triceps samples, citrate levels were unchanged $(0.85$ to 0.72 from before to after training; $P=0.40$; Fig. $4 B$ ). Citrate is commonly added to food, where it acts as a mild antioxidant and food preservative by chelation of divalent iron. We hypothesized that the inactivation of aconitase and resulting increase in citrate are important steps in the restoration of the cellular redox state. We therefore investigated the cytoprotective effects of citrate after oxidative stress induced by externally added $\mathrm{H}_{2} \mathrm{O}_{2}$. When cultured primary myotubes were exposed to 50-200 $\mathrm{MM} \mathrm{H}_{2} \mathrm{O}_{2}$ for $24 \mathrm{~h}$, cellular mitochondrial content decreased significantly, as assessed by the protein content of CS (Fig. 4C). Addition of $10 \mathrm{mM}$ sodium citrate fully abolished this degradation, indicating that citrate protected mitochondrial proteins from oxidative stress and mitophagy (Fig. 4D).

\section{DISCUSSION}

In the present study, aconitase acted as a sensitive redoxregulated protein, responding to exercise and oxidative stress by inactivation, which led to inhibition of the mitochondrial 
A

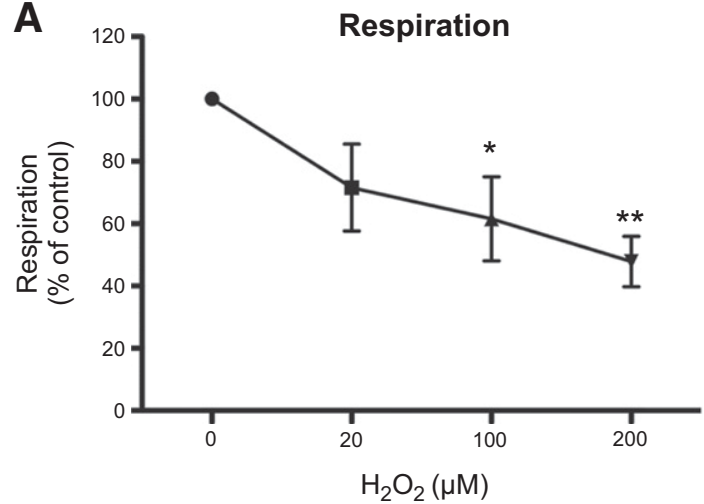

C

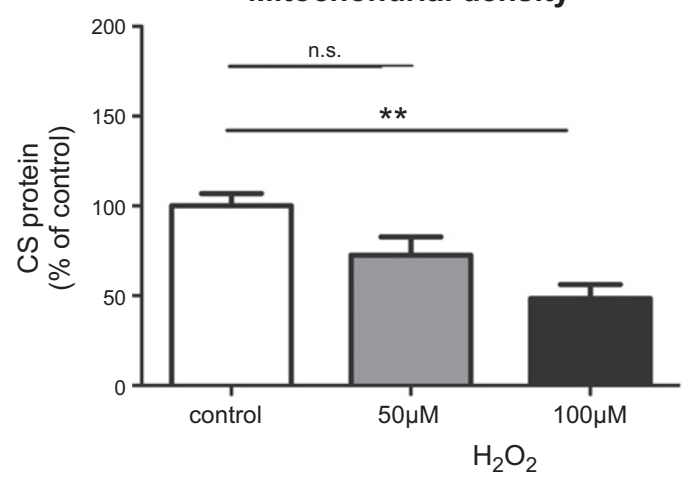

B

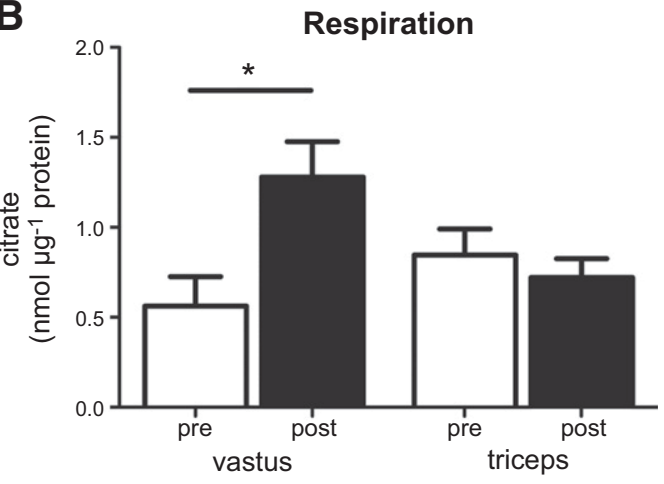

D

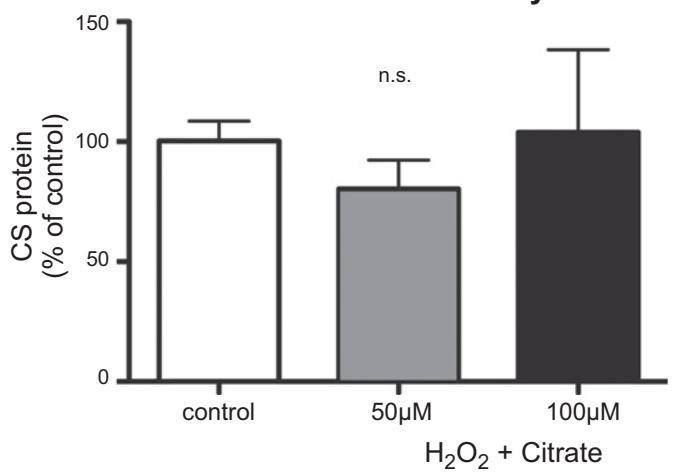

Figure 4. Functional effects of training in skeletal muscle and exposure to $\mathrm{H}_{2} \mathrm{O}_{2}$ in myotubes. $A$ ) Inhibition of respiration in myotubes after $\mathrm{H}_{2} \mathrm{O}_{2}$ exposure. Human primary myotubes were permeabilized with digitonin and acutely exposed to increasing concentrations of $\mathrm{H}_{2} \mathrm{O}_{2}$. Respiration was measured by high-resolution respirometry $(n=3)$. B) Citrate content in muscle homogenates before and after exercise, measured before and after training with a spectrophotometer $(n=5-6)$. $C, D)$ Human primary myotubes were exposed to control or $\mathrm{H}_{2} \mathrm{O}_{2}$ in the absence $(C)$ or presence $(D)$ of $10 \mathrm{mM}$ citrate for $24 \mathrm{~h}$. Mitochondrial density was assessed by the protein content of CS. A matched control set of experiments was obtained for each treatment $(n=5-7)$. Error bars, sEM. $* P<0.05 ; * * P<0.01$.

respiration that protects the cell from further oxidative stress. As aconitase was inactivated, citrate accumulated and protected the mitochondria from oxidative degradation. Simultaneously, mitochondrial density increased, to maintain muscle oxidative capacity and the energy status of the cell. Excessive inhibition of aconitase, as seen in the triceps, not only inhibited mitochondrial respiration, but also abolished the increase in citrate and mitochondrial density and induced a parallel robust activation of the endogenous antioxidant catalase that restored redox homeostasis.

Aconitase is present in 2 isoforms: one is mitochondrial the other cytosolic. The mitochondrial isoform is predominant in skeletal muscle (22) and is a part of the TCA cycle, where it forms a vital structure in mitochondrial ATP production. The cytosolic isoform is involved in iron metabolism (23). Exercise has been linked to elevated levels of ROS production, and aconitase is readily inactivated by ROS. It has been proposed that aconitase is inactivated during intense exercise. However, whether this occurs in vivo is not fully clear. One study found inactivation of aconitase after exhaustive exercise in rats (24), whereas another study involving human subjects showed increased aconitase activity after an acute bout of medium-intensity exercise (25). That the clinical manifestations of Friedrich ataxia, a mitochondrial disorder characterized by aconitase deficiency, are severe exercise intolerance, fatigue, and progressive damage of the nervous system is interesting and indicates that functional aconitase is essential in maintaining redox balance and the cellular antioxidant defense system.

In this study, we found evidence of a profound mitochondrial aconitase inactivation by a brief period of HIT. After HIT training, aconitase activity per mitochondria was reduced to 45 and $28 \%$ of the pretraining value in the vastus and triceps, respectively. The moderate reduction in the vastus was compensated for by increased mitochondrial biogenesis, which appeared to occur in parallel. When aconitase activity was expressed per unit of wet weight muscle we found a similar level in the vastus before and after training, whereas activity in the triceps was still was only $57 \%$ of the pretraining value. The finding that other mitochondrial enzymes increased in parallel with aconitase inhibition as a compensatory mechanism bears strong resemblance to a pathologic aconitase deficiency, as affected patients have higher mitochondrial densities than matched controls (22). The observed difference between the vastus and triceps indicates that the triceps was under more severe oxidative stress during HIT and could not fully compensate for the reduction in aconitase activity by increasing mitochondrial density. The functional impact of aconitase inhibition manifested in 
the reduction in respiration per milligram mitochondria after training in both the vastus and triceps. Mitochondrial biogenesis compensated for this bioenergy loss in the vastus, given that mitochondrial proteins were up-regulated in the range of $15-72 \%$ after training. However, we found no significant increase in triceps muscle mitochondrial proteins after training. It should be noted that we observed a much more homogenous change in mitochondrial proteins in the vastus, which contributed to the statistical significance in this muscle group, whereas there was more variation in the triceps. Although a significant change in mitochondrial density markers was not noted in the triceps, it may still play a role in the adaptation to buffering the ROS produced from HIT.

To probe whether the different MHC distributions between arm and leg contributed to our observations, we ran correlation analyses between both the inhibition of mitochondrial respiration and aconitase inactivation against the baseline MHC distribution. We found no convincing associations between any of these variables and cannot state that the MHC composition contributed to our findings. However, we cannot exclude a fiber-type-linked mechanism underlying the compensatory reduction in mitochondrial ROS production and antioxidant response between arms and legs. This possibility warrants further investigation.

Mitochondria are important sources of ROS production, and down-regulation of mitochondrial activity and ROS production could constitute a sophisticated cellular response to quickly restore redox homeostasis. Pharmacological inhibition of complex I-mediated respiration by rotenone has been found to increase mitochondrial ROS production, with deleterious cellular consequences (26). We found unexpectedly that $\mathrm{H}_{2} \mathrm{O}_{2}$ emission after training was reduced to $40 \%$ of the pretraining value in triceps, whereas it was unchanged in the vastus, demonstrating a more severe oxidative challenge in the triceps. Secondary to a reduction in mitochondrial ROS production, a more chronic adaptation to elevated oxidative stress, is the biogenesis of enzymes of the antioxidant defense system. In triceps tissue we found a 6 -fold induction after training of protein levels of the $\mathrm{H}_{2} \mathrm{O}_{2}$-scavenging enzyme catalase. Consistent with the finding that oxidative stress was less severe in the vastus, no significant increase in catalase was found in this muscle group.

The functional impact of attenuated mitochondrial respiratory capacity, as a component of the $\mathrm{O}_{2}$ cascade contributing to $\mathrm{Vo}_{2 \text { peak }}$, and exercise capacity with this form of training is noteworthy. Despite a rather marked mitochondrial inhibition, both exercise capacity and $\mathrm{VO}_{\text {2peak }}$ increased in the present study. This finding substantiates the apparent overcapacity of mitochondrial respiration compared to the capacity to deliver oxygen to the working tissue (27). One function of this overcapacity could be to constitute a necessary buffer to avoid energy limitations caused by oxidative inactivation by aconitase and thereby mitochondrial respiration. The improvements in $V_{2}$ peak could be attributable to structural and functional components unrelated to intrinsic mitochondrial capacity (28).

A striking result in this study was the opposing response to training of 2 adjacent enzymes of the TCA cycle. The increased protein content and activity of CS and the inactivation of aconitase infers that citrate should accumulate. Apart from being a TCA cycle intermediate, citrate also inhibits phosphofructokinase and acts as a metabolic sensor [for a review, see Iacobazzi and Infantino (29)]. We hypothesized that the increase in cellular citrate content is an integral part of the antioxidative defense system. In support of this assumption, when we added citrate to the medium of cultured myotubes, it fully abolished the mitophagic response to a challenge with $\mathrm{H}_{2} \mathrm{O}_{2}$ (Fig $\left.4 C, D\right)$. Citrate has also been shown to play an intricate role in
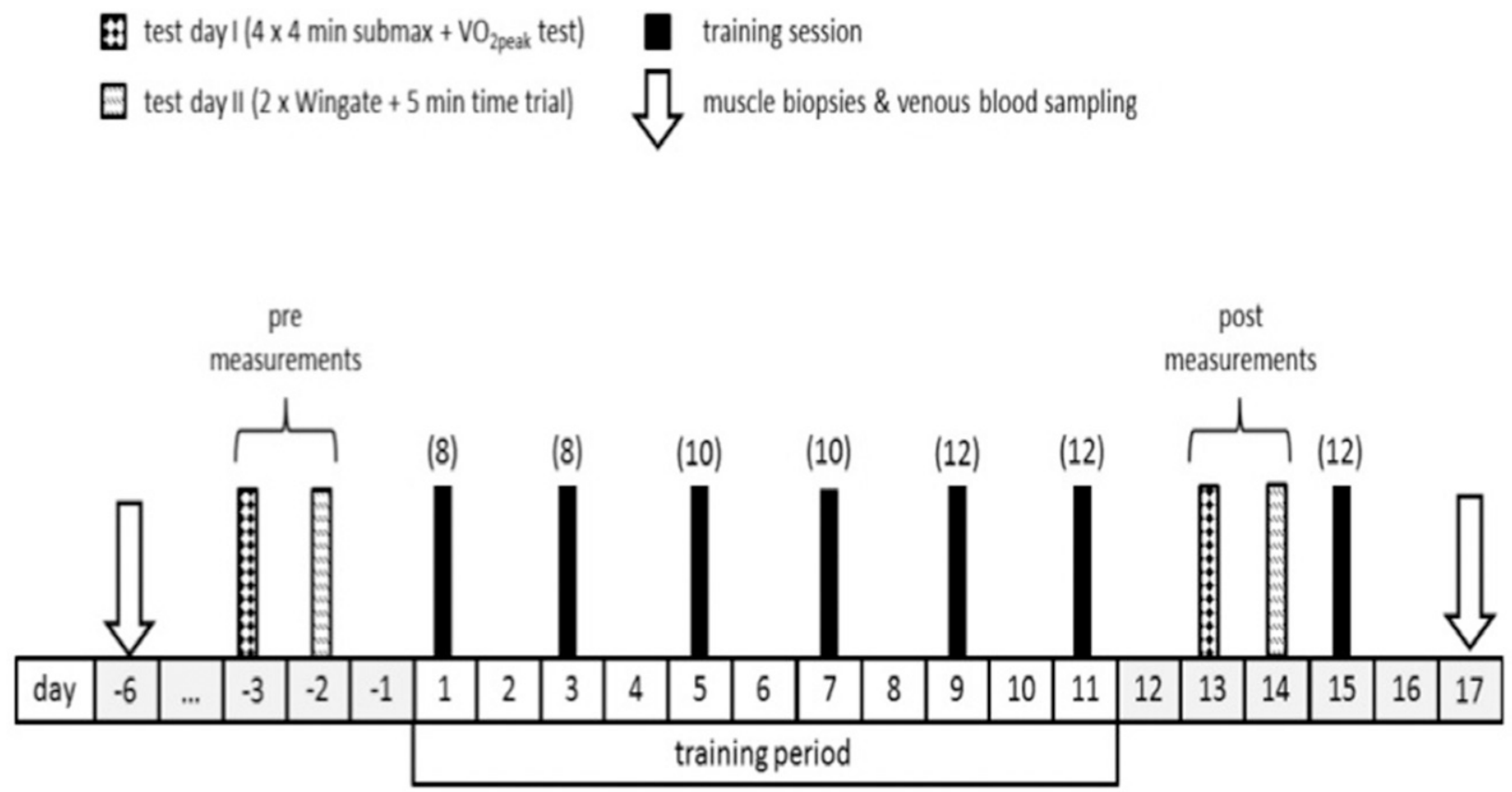

Scheme 1. The experimental protocol. The numbers in parentheses indicate the number of $30 \mathrm{~s}$ sprints per training session. 
metabolic control through its diverse chemical properties and ability to interact with other biochemical pathways, especially phosphofructokinase, which inhibits glycolysis (29). Another interesting finding is that the reactivation of aconitase after oxidative stress is fully dependent on the presence of citrate through an interaction with frataxin (30). Citrate is also a known chelator of divalent cations, such as $\mathrm{Fe}^{2+}$, and thereby indirectly interferes with the Fenton reaction between iron and $\mathrm{H}_{2} \mathrm{O}_{2}$, likely effecting the production of hydroxyl radicals. The activity of CS has for unknown reasons been shown to increase after an acute bout of endurance exercise (31), and citrate release from skeletal muscles is increased during exercise (32). It can be speculated that the increase in citrate formation during exercise is not only a reflection of the TCA cycle intermediate pool but also a functional response to protect the muscle cell against oxidative stress.

The contrasting response to HIT between the vastus and triceps in the present study is intriguing. It is clear that there is a dose-response relationship between ROS production and cellular outcome. Several studies have indicated that mild oxidative stress is necessary for initiation of the adaptive response to exercise, in that administration of dietary antioxidants can prevent the beneficial effects of an exercise program $(6,33)$. However, severe oxidative stress in pathologic conditions or during overtraining can lead to maladaptation, with detrimental long-term effects (34). The results of the present study indicate that oxidative stress in the vastus had less severe consequences, because the inactivation of mitochondrial aconitase was compensated for by an increase in mitochondrial density. On the contrary, several lines of evidence indicate that oxidative stress was excessive in the triceps. First, the absence of increases in mitochondrial density indicates that this muscle group did not respond to training as expected. The lack of increase in mitochondrial density resulted in a lower aconitase activity per milligram tissue after training. In addition, mitochondrial $\mathrm{H}_{2} \mathrm{O}_{2}$ emission was reduced

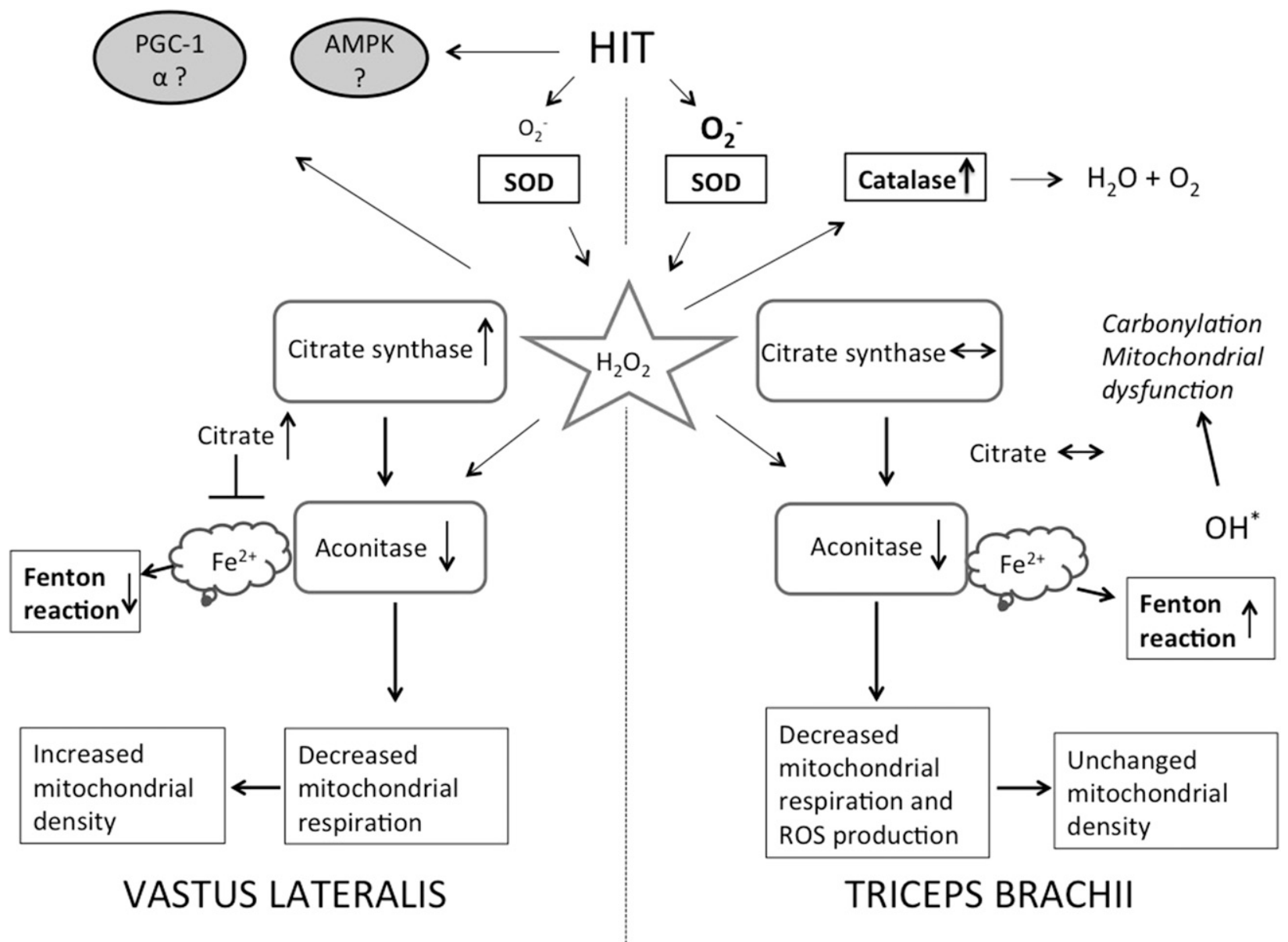

Scheme 2. The skeletal muscle mitochondrial response to HIT. Exercise induces superoxide production to different degrees, depending on muscle group. In the triceps, catalase expression is increased, whereas it is unchanged in the vastus. $\mathrm{H}_{2} \mathrm{O}_{2}$ inactivates aconitase and, as a consequence, mitochondrial respiration is inhibited. In triceps, mitochondrial ROS production decreases in parallel. With decreased mitochondrial respiration, the capacity to produce ATP is diminished. This lowered energy state is sensed and, if oxidative stress is within the antioxidant capacity of the cell (as in the vastus), it is compensated for by increasing global mitochondrial density. As CS is markedly increased and aconitase inactivated, citrate accumulates in the tissue and protects the mitochondria from oxidative degradation. If oxidative stress exceeds a certain threshold (as in the triceps), however, the biogenesis of catalase is initiated to protect against further damage by $\mathrm{H}_{2} \mathrm{O}_{2}$. The mitochondrial biogenesis process fails to increase mitochondrial density, and CS and other mitochondrial proteins also do not increase. Thereby, a negative loop of events is initiated, because citrate does not increase, leaving the mitochondria even more prone to oxidative degradation, with loss of cellular energy capacity. 
after training, most likely a response to counteract oxidative stress. Further, a near significant increase in protein carbonyl products was found in triceps homogenates. Last, protein content of catalase was increased by more than 6fold, a logical response to increased cellular levels of $\mathrm{H}_{2} \mathrm{O}_{2}$. The present data suggest that the vastus responds to training as expected, with a functional increase in mitochondrial density, probably mediated by mild oxidative stress that initiates crucial signaling events. Despite the similar training stimuli between arm and leg exercise, the triceps seemed to be more vulnerable to oxidative stress induced by HIT, as indicated by the increased oxidative stress markers and maladaptive response to training. The origin of this different response between the vastus and triceps can only be speculated upon. Whether the differentiated response in the triceps $v$ s. the vastus is dependent on intrinsic characteristics of the specific limb muscles or degree of muscle use is not obvious. Even though the subjects in this study were untrained, they had aboveaverage aerobic capacity, as measured by $V_{2}{ }_{2 p e a k}$ testing. Nonetheless, that humans are more accustomed to regular use of leg muscles for locomotion could explain the findings in this study. It is likely that a period of exercise training with lower intensity before the more intense sprint training preconditions the muscle cells against the oxidative stress and potentiate the cellular adaptations. Indeed, it has recently been shown that a period of low-intensity exercise protects dystrophin-deficient MDX mice that are vulnerable to the oxidative stress induced by high-intensity exercise (35). The lower training status of the triceps could therefore be a part of the explanation of the maladaptation to intense exercise in this muscle group.

In summary, we show that a short-term, intense exercise program in previously untrained subjects induces oxidative stress that inactivates aconitase and initiates an orchestrated cellular response to re-establish the redox balance and energy status of the cell. A proposed chain of events is illustrated in Schemes 1 and 2.

This study was funded by Swedish National Centre for Research in Sports. D.M.-A. is a fellow of the Dr. Manuel Morales Foundation. The authors declare no conflicts of interest.

\section{REFERENCES}

1. Russell, A. P., Foletta, V. C., Snow, R. J., and Wadley, G. D. (2014) Skeletal muscle mitochondria: a major player in exercise, health and disease. Biochim. Biophys. Acta 1840, 1276-1284

2. Holloszy, J. O., Oscai, L. B., Don, I. J., and Molé, P. A. (1970) Mitochondrial citric acid cycle and related enzymes: adaptive response to exercise. Biochem. Biophys. Res. Commun. 40, 1368-1373

3. Phielix, E., Schrauwen-Hinderling, V. B., Mensink, M., Lenaers, E., Meex, R., Hoeks, J., Kooi, M. E., Moonen-Kornips, E., Sels, J. P., Hesselink, M. K., and Schrauwen, P. (2008) Lower intrinsic ADPstimulated mitochondrial respiration underlies in vivo mitochondrial dysfunction in muscle of male type 2 diabetic patients. Diabetes 57, 2943-2949

4. Larsen, F. J., Schiffer, T. A., Borniquel, S., Sahlin, K., Ekblom, B., Lundberg, J. O., and Weitzberg, E. (2011) Dietary inorganic nitrate improves mitochondrial efficiency in humans. Cell Metab. 13, 149-159

5. Jacobs, R. A., Fluck, D., Bonne, T. C., Burgi, S., Christensen, P. M., Toigo, M., Lundby, C. (2013) Improvements in exercise performance with high-intensity interval training coincide with an increase in skeletal muscle mitochondrial content and function. J. Appl. Physiol. 115, 785-793

6. Paulsen, G., Cumming, K. T., Holden, G., Hallén, J., Rønnestad, B. R., Sveen, O., Skaug, A., Paur, I., Bastani, N. E., Østgaard, H. N., Buer, C., Midttun, M., Freuchen, F., Wiig, H., Ulseth, E. T., Garthe, I., Blomhoff, R., Benestad, H. B., and Raastad, T. (2014) Vitamin C and $\mathrm{E}$ supplementation hampers cellular adaptation to endurance training in humans: a double-blind, randomised, controlled trial. J. Physiol. 592, 1887-1901

7. Liu, L., Zhang, K., Sandoval, H., Yamamoto, S., Jaiswal, M., Sanz, E., Li, Z., Hui, J., Graham, B. H., Quintana, A., and Bellen, H. J. (2015) Glial lipid droplets and ROS induced by mitochondrial defects promote neurodegeneration. Cell 160, 177-190

8. Skenderi, K. P., Tsironi, M., Lazaropoulou, C., Anastasiou, C. A., Matalas, A. L., Kanavaki, I., Thalmann, M., Goussetis, E., Papassotiriou, I., and Chrousos, G. P. (2008) Changes in free radical generation and antioxidant capacity during ultramarathon foot race. Eur. J. Clin. Invest. 38, 159-165

9. Sahlin, K., Shabalina, I. G., Mattsson, C. M., Bakkman, L., Fernstrom, M., Rozhdestvenskaya, Z., Enqvist, J. K., Nedergaard, J., Ekblom, B., Tonkonogi, M. (2010) Ultraendurance exercise increases the production of reactive oxygen species in isolated mitochondria from human skeletal muscle. J. Appl. Physiol. 108, 780-787

10. Cobley, J. N., McHardy, H., Morton, J. P., Nikolaidis, M. G., and Close, G. L. (2015) Influence of vitamin C and vitamin $\mathrm{E}$ on redox signaling: Implications for exercise adaptations. Free Radic. Biol. Med. 84, 65-76

11. Ristow, M., and Zarse, K. (2010) How increased oxidative stress promotes longevity and metabolic health: The concept of mitochondrial hormesis (mitohormesis). Exp. Gerontol. 45, 410-418

12. Davies, K. J., Quintanilha, A. T., Brooks, G. A., and Packer, L. (1982) Free radicals and tissue damage produced by exercise. Biochem. Biophys. Res. Commun. 107, 1198-1205

13. Viña, J., Gimeno, A., Sastre, J., Desco, C., Asensi, M., Pallardó, F. V., Cuesta, A., Ferrero, J. A., Terada, L. S., and Repine, J. E. (2000) Mechanism of free radical production in exhaustive exercise in humans and rats; role of xanthine oxidase and protection by allopurinol. IUBMB Life 49, 539-544

14. Sakellariou, G. K., Vasilaki, A., Palomero, J., Kayani, A., Zibrik, L., McArdle, A., and Jackson, M. J. (2013) Studies of mitochondrial and nonmitochondrial sources implicate nicotinamide adenine dinucleotide phosphate oxidase(s) in the increased skeletal muscle superoxide generation that occurs during contractile activity. Antioxid. Redox Signal. 18, 603-621

15. Pearson, T., Kabayo, T., Ng, R., Chamberlain, J., McArdle, A., and Jackson, M. J. (2014) Skeletal muscle contractions induce acute changes in cytosolic superoxide, but slower responses in mitochondrial superoxide and cellular hydrogen peroxide. PLoS One 9, e96378

16. Armstrong, J. S., Whiteman, M., Yang, H., and Jones, D. P. (2004) The redox regulation of intermediary metabolism by a superoxideaconitase rheostat. BioEssays: 26, 894-900

17. Brink-Elfegoun, T., Kaijser, L., Gustafsson, T., and Ekblom, B. (2007) Maximal oxygen uptake is not limited by a central nervous system governor. J. Appl. Physiol. 102, 781-786

18. Poole, D.C., Barstow, T.J., McDonough, P., Jones, A.M. Control of oxygen uptake during exercise. (2008) Med Sci Sports Exerc. 40, $462-747$

19. Larsen, F. J., Schiffer, T. A., Sahlin, K., Ekblom, B., Weitzberg, E., and Lundberg, J. O. (2011) Mitochondrial oxygen affinity predicts basal metabolic rate in humans. FASEB J. 25, 2843-2852

20. Andersson, U., Leighton, B., Young, M. E., Blomstrand, E., and Newsholme, E. A. (1998) Inactivation of aconitase and oxoglutarate dehydrogenase in skeletal muscle in vitro by superoxide anions and/or nitric oxide. Biochem. Biophys. Res. Commun. 249, 512-516

21. Blomstrand, E., Rådegran, G., and Saltin, B. (1997) Maximum rate of oxygen uptake by human skeletal muscle in relation to maximal activities of enzymes in the Krebs cycle. J. Physiol. 501, $455-460$

22. Haller, R. G., Henriksson, K. G., Jorfeldt, L., Hultman, E., Wibom, R., Sahlin, K., Areskog, N. H., Gunder, M., Ayyad, K., Blomqvist, C. G., et al. (1991) Deficiency of skeletal muscle succinate dehydrogenase and aconitase. Pathophysiology of exercise in a novel human muscle oxidative defect. J. Clin. Invest. 88, 1197-1206

23. Narahari, J., Ma, R., Wang, M., and Walden, W. E. (2000) The aconitase function of iron regulatory protein 1 . Genetic studies in 
yeast implicate its role in iron-mediated redox regulation. J. Biol. Chem. 275, 16227-16234

24. Ho, K. P., Xiao, D. S., Ke, Y., and Qian, Z. M. (2001) Exercise decreases cytosolic aconitase activity in the liver, spleen, and bone marrow in rats. Biochem. Biophys. Res. Commun. 282, 264-267

25. Zhang, S. J., Sandström, M. E., Lanner, J. T., Thorell, A., Westerblad, H., and Katz, A. (2007) Activation of aconitase in mouse fast-twitch skeletal muscle during contraction-mediated oxidative stress. $\mathrm{Am}$. J. Physiol. Cell Physiol. 293, C1154-C1159

26. Li, N., Ragheb, K., Lawler, G., Sturgis, J., Rajwa, B., Melendez, J. A., and Robinson, J. P. (2003) Mitochondrial complex I inhibitor rotenone induces apoptosis through enhancing mitochondrial reactive oxygen species production. J. Biol. Chem. 278, 8516-8525

27. Boushel, R., Gnaiger, E., Calbet, J. A., Gonzalez-Alonso, J., Wright-Paradis, C., Sondergaard, H., Ara, I., Helge, J. W., and Saltin, B. (2011) Muscle mitochondrial capacity exceeds maximal oxygen delivery in humans. Mitochondrion 11, 303-307

28. Boushel, R., Ara, I., Gnaiger, E., Helge, J. W., González-Alonso, J., Munck-Andersen, T., Sondergaard, H., Damsgaard, R., van Hall, G., Saltin, B., and Calbet, J. A. (2014) Low-intensity training increases peak arm $\mathrm{VO}_{2}$ by enhancing both convective and diffusive $\mathrm{O} 2$ delivery. Acta Physiol. (Oxf.) 211, 122-134

29. Iacobazzi, V., and Infantino, V. (2014) Citrate-new functions for an old metabolite. Biol. Chem. 395, 387-399

30. Bulteau, A. L., O’Neill, H. A., Kennedy, M. C., Ikeda-Saito, M., Isaya, G., and Szweda, L. I. (2004) Frataxin acts as an iron chaperone protein to modulate mitochondrial aconitase activity. Science $\mathbf{3 0 5}$, 242-245

31. Tonkonogi, M., Harris, B., and Sahlin, K. (1997) Increased activity of citrate synthase in human skeletal muscle after a single bout of prolonged exercise. Acta Physiol. Scand. 161, $435-436$

32. Jansson, E., and Kaijser, L. (1984) Leg citrate metabolism at rest and during exercise in relation to diet and substrate utilization in man. Acta Physiol. Scand. 122, 145-153

33. Ristow, M., Zarse, K., Oberbach, A., Klöting, N., Birringer, M., Kiehntopf, M., Stumvoll, M., Kahn, C. R., and Blüher, M. (2009) Antioxidants prevent health-promoting effects of physical exercise in humans. Proc. Natl. Acad. Sci. USA 106, $8665-8670$

34. Westerblad, H., and Allen, D. G. (2011) Emerging roles of ROS/ RNS in muscle function and fatigue. Antioxid. Redox Signal. 15 , 2487-2499

35. Hyzewicz, J., Tanihata, J., Kuraoka, M., Ito, N., Miyagoe-Suzuki, Y., and Takeda, S. (2015) Low intensity training of mdx mice reduces carbonylation and increases expression levels of proteins involved in energy metabolism and muscle contraction. Free Radic. Biol. Med. 82, 122-136

Received for publication May 29, 2015. Accepted for publication September 14, 2015. 


\section{THE}

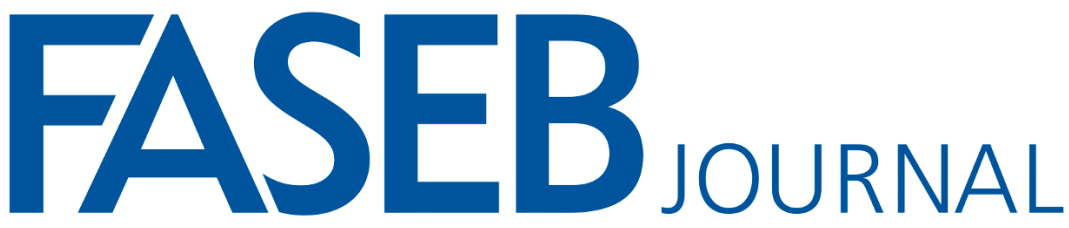

The Journal of the Federation of American Societies for Experimental Biology

\section{High-intensity sprint training inhibits mitochondrial respiration through aconitase inactivation}

Filip J. Larsen, Tomas A. Schiffer, Niels Ørtenblad, et al.

FASEB J 2016 30: 417-427 originally published online October 9, 2015

Access the most recent version at doi:10.1096/fj.15-276857

Supplemental
Material

References This article cites 29 articles, 6 of which can be accessed free at: http://www.fasebj.org/content/30/1/417.full.html\#ref-list-1

Subscriptions Information about subscribing to The FASEB Journal is online at http://www.faseb.org/The-FASEB-Journal/Librarian-s-Resources.aspx

Permissions Submit copyright permission requests at:

http://www.fasebj.org/site/misc/copyright.xhtml

Email Alerts Receive free email alerts when new an article cites this article - sign up at http://www.fasebj.org/cgi/alerts

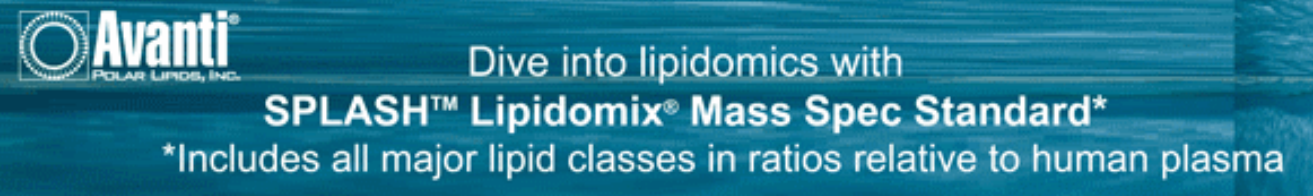

C) FASEB 